\title{
Relationships between bone mineral density and new indices of body composition in young, sedentary men and women
}

\author{
Anna Kęska', Grażyna Lutosławska', Jerzy Bertrandt' ${ }^{2}$, Małgorzata Sobczak ${ }^{3}$ \\ ${ }^{1}$ Department of Biochemistry and Biology, University of Physical Education, Warsaw, Poland \\ 2 Department of Hygiene and Epidemiology, Military Institute of Hygiene and Epidemiology, Warsaw, Poland \\ ${ }^{3}$ Department of Public Health, Warsaw University, Poland
}

Kęska A, Lutosławska G, Bertrandt J, Sobczak M.. Relationships between bone mineral density and new indices of body composition in young, sedentary men and women. Ann Agric Environ Med. 2018; 25(1): 23-25. doi: 10.5604/12321966.1233562

\begin{abstract}
Introduction. Data concerning the relationship between body fat and BMD are equivocal since both positive and negative effects have been noted. Recently, the index of fat mass (IFM) representing subjects with different body fat and similar lean mass and index of lean mass (ILM) representing subjects with different lean body mass and similar body fat, have been used to evaluate body composition effect on BMD in middle-aged women. This study aimed at determination of ILM and IFM association with BMD in young men and women.

Materials and methods. A total of 212 university students of Public Health (125 women and 87 men) participated in the study. Body composition was determined by the bioelectrical impedance method (BIA) using BC 418 MA equipment (Tanita Co., Japan). Fat mass and fat free mass were used to calculate ILM and IFM. Bone mineral density was measured on the wrist of the non-dominant hand using the DEXA method and EXA 3000 equipment (HFS Ltd., Korea). BMD was evaluated using Z-score, with values lower than -2.0 indicating inadequate BMD for subject chronological age.

Results. Exclusively in women, IFM was markedly and positively correlated with Z-score $(r=0.366, P<0.001)$. In both genders, a significant relationship was found between ILM and Z-scores $(r=0.420 ; p<0.001$ and $r=0.220 ; p<0.02$ in men and women, respectively). Women with lower than median IFM but similar ILM, were characterized by significantly lower Z-scores vs. women with higher IFM (-1.016 vs. $-0.512 ; \mathrm{p}<0.001)$. Irrespective of gender, participants with higher ILM but similar IFM, were characterized by markedly higher Z-score vs. their counterparts with low ILM.

Conclusions. The use of IFM and ILM in the present study, allowed the observation that in young adults lean body mass was associated with BMD, regardless of gender, while fat mass is significant for bone mineral density only in women.
\end{abstract}

\section{Key words}

young adults, gender, bone mineral density, body composition

\section{INTRODUCTION}

Among many factors affecting bone mass, body weight is a strong and positive predictor acting through mechanical stress, which in turn increases osteogenesis and bone mineral density (BMD) [1]. In turn, it has been suggested that the reduction in body weight brings about bone loss [2]. However, it should be stressed that body weight consists of two major components - fat mass (FM) and lean mass (LM) both contributing to mechanical stress, and many efforts have been made to establish their individual impact on bone health [3].

There is no doubt that LM exerts a positive influence on bone structure [4]. In contrast, decrease in LM due to age-related sarcopenia is responsible for low BMD [5]. Additionally, irrespectively of age, a weight-bearing exercise which increases LM also positively affects BMD [6]. On the contrary, data concerning the relationship between FM and $\mathrm{BMD}$ are equivocal since both positive and negative effects of body fatness on BMD have been noted [7,8]. The reason for this discrepancy is unknown; however, it seems that fat-derived adipokines may exert either positive and/or

Addres for correspondence: Anna Kęska, PhD, Department of Biochemistry and Biology, University of Physical Education, Box 55, 01-968 Warsaw 45, Poland Tel: +48228340431 ext. 261

E-mail: Anna.Keska@awf.edu.pl

Received: 22 July 2014; accepted: 14 April 2015; first published on February 2017 negative action on BMD $[9,10]$. It should be stressed that FM associations with BMD are of special importance in women characterized by lower BMD than men, and increased risk of osteoporosis at menopausal transition [11]. However, even this issue is controversial. Makovey et al. [12] demonstrated that in both genders BMD is mostly affected by lean body mass, with positive effect of fat mass exclusively in women under 50 years old, but not in older ones. In contrast, Yoo et al. [13] found negative effects of body fat on BMD exclusively in premenopausal women. There are also data suggesting that it is not total body fat, but android fat distribution that affects bone health decrease in both BMD and BMC in middleage subjects [14]. More recent data have suggested that age, gender and race are more important for bone health than body composition [15]. However, it could not be excluded that the above-mentioned discrepancy is due to different methods used in body shape evaluation (easily calculated surrogate indices of body fat as body mass index and waist to hip ratio, or precisely calculated index of fat mass) [13-15].

Recently, Nouvenne et al. [16] introduced new indices of body composition - index of fat mass (IFM) representing subjects with different body fat and similar lean mass, and index of lean mass (ILM) representing subjects with different lean body mass and similar body fat. Until now, both indices have been found to affect BMD in middle-aged premenopausal and menopausal women. 


\section{OBJECTIVE}

The study was undertaken to elucidate the validity of IFM and ILM in anticipation of BMD, and to evaluate IFM and ILM effects on BMD in young adults of both genders.

\section{MATERIALS AND METHOD}

A total of 212 university students of Public Health (125 women and 87 men) participated in the study, recruited on the basis of advertisements in student dormitories and by word of mouth. All volunteers were healthy, non-smokers, and not using any medications on a regular basis. Their physical activity was less than $3 \mathrm{~h}$ /week. All participants declared no eating disorders and all women were regularly menstruating. The study was approved by the local Ethics Committee and informed written consent was obtained from each participant.

Basic anthropometric parameters, such as body mass and height, were evaluated using standard medical scales. Body composition was determined by the bioelectrical impedance method (BIA) using BC 418 MA equipment (Tanita Co., Japan). Inter- and intra-assay coefficients of variation for body fat measurements did not exceed $2 \%$. Fat mass (FM) and lean mass (LM) were further used to calculate ILM and IFM, according to a formula proposed by Nouvenne et al. [16]:

Index of fat mass (IFM): IFM $=(\mathrm{LM}+\mathrm{FM}) /(\mathrm{LM}-\mathrm{FM})$; Index of lean mass (ILM): ILM $=\mathrm{LM}^{2}-\mathrm{FM}^{2}$

Both male and female participants were divided in two groups according to median value of either IFM or ILM.

Bone mineral density was measured on the wrist of the non-dominant hand using DEXA method and the EXA 3000 equipment (HFS Ltd., Korea). BMD was evaluated according to the WHO recommendations, by using a Z-score with values lower than -2.0 indicating inadequate BMD for subject of chronological age [17].

Descriptive statistics are presented as means \pm SD. Data distribution was evaluated using the Shapiro-Wilk test. The Mann-Whitney U test was applied for comparison of data with respect to gender. Spearman rank correlations were evaluated between $\mathrm{Z}$-score and anthropometric variables. Values of $\mathrm{p}<0.05$ were accepted as significant. All analyses were performed using Statistica v.10. (Stat Soft, USA).

\section{RESULTS}

Women in the study were characterized by a significantly higher percentage of body fat and IFM compared to men $(\mathrm{P}<0.001)$ (Tab. 1). On the other hand, in male participants, significantly higher values of ILM were noted $(p<0.001)$. $\mathrm{Z}$-score values were also higher in men vs. women $(\mathrm{p}<0.001)$. In $92.8 \%$ of women and $97.7 \%$ of men participating in the study, Z-score values were higher than -2.0 .

In men, no relationship was noted between IFM and Z-score. In contrast, in women, IFM was markedly and positively correlated with $\mathrm{Z}$-score $(\mathrm{r}=0.366$; $\mathrm{p}<0.001)$. In both genders, a significant relationship was found between ILM and $\mathrm{Z}$-scores $(\mathrm{r}=0.420 ; \mathrm{p}<0.001$ and $\mathrm{r}=0.220 ; \mathrm{p}<0.02)$, in men and women, respectively.
Table 1. Anthropometric characteristics and bone mineral density of young men and women (mean \pm SD)

\begin{tabular}{lcc}
\hline Variables & $\begin{array}{c}\text { Women } \\
(\mathrm{n}=125)\end{array}$ & $\begin{array}{c}\text { Men } \\
(\mathrm{n}=87)\end{array}$ \\
\hline Age $(\mathrm{yrs})$ & $22.7 \pm 2.6$ & $23.2 \pm 3.2$ \\
\hline Weight $(\mathrm{kg})$ & $61.4 \pm 13.2^{* *}$ & $80.1 \pm 12.0$ \\
\hline Height $(\mathrm{cm})$ & $165.5 \pm 6.0^{* *}$ & $179.7 \pm 5.7$ \\
\hline Fat $(\%)$ & $26.0 \pm 7.9^{* *}$ & $15.8 \pm 5.3$ \\
\hline Fat $(\mathrm{kg})$ & $17.0 \pm 8.5^{*}$ & $13.1 \pm 5.9$ \\
\hline FFM $(\mathrm{kg})$ & $45.0 \pm 7.2^{* *}$ & $66.9 \pm 7.8$ \\
\hline IFM & $2.46 \pm 1.35^{* *}$ & $1.50 \pm 0.26$ \\
\hline ILM & $1714.0 \pm 780.8^{* *}$ & $4331.0 \pm 957.8$ \\
\hline Z-score & $-0.775 \pm 0.766^{* *}$ & $-0.428 \pm 0.727$ \\
\hline
\end{tabular}

FFM- fat free mass; IFM - index of fat mass; ILM - index of lean mass; ${ }^{*} \mathrm{P}<0.01 ;{ }^{*} \mathrm{P}<0.001$ significantly different vs. men; ^ percent of subjects with adequate BMD according to chronological age

Women with lower than median IFM but similar ILM, were characterized by significantly lower Z-scores vs. women with higher IFM $(\mathrm{p}<0.001)(\mathrm{Tab} .2)$. In contrast, in males, differences in IFM did not affect Z-score.

Table 2. Anthropometric characteristics of participants divided into groups according to IFM median value

\begin{tabular}{lcccc}
\hline \multirow{2}{*}{ Variable } & \multicolumn{2}{c}{ Women $(\mathrm{n}=125)$} & \multicolumn{2}{c}{ Men $(\mathrm{n}=87)$} \\
\cline { 2 - 5 } & $\mathrm{IFM}<1.99$ & $\mathrm{IFM}>1.99$ & $\mathrm{IFM}<1.46$ & $\mathrm{IFM}>1.46$ \\
$(\mathrm{n}=64)$ & $(\mathrm{n}=61)$ & $(\mathrm{n}=44)$ & $73)$ \\
\hline Fat $(\mathrm{kg})$ & $11.1 \pm 2.9^{* * *}$ & $23.3 \pm 8.0$ & $7.8 \pm 2.8^{* * *}$ & $17.6 \pm 4.3$ \\
\hline FFM $(\mathrm{kg})$ & $43.4 \pm 8.1^{* * *}$ & $46.7 \pm 5.6$ & $65.0 \pm 7.7^{* * *}$ & $70.2 \pm 7.0$ \\
\hline IFM & $1.70 \pm 0.18^{* * *}$ & $3.27 \pm 1.57$ & $1.27 \pm 0.10^{* * *}$ & $1.69 \pm 0.24$ \\
\hline ILM & $1819.3 \pm 1033.1$ & $1599.8 \pm 312.4$ & $4210.5 \pm 1000.2$ & $4646.4 \pm 943.2$ \\
\hline Z-score & $-1.016 \pm 0.723^{* * *}$ & $-0.512 \pm 0.742$ & $-0.123 \pm 0.777$ & $-0.301 \pm 0.693$ \\
\hline FFM - fat free mass; IFM - index of fat mass; ILM - index of lean mass. \\
*P<0.01;**P<0.001 significantly different vs. subjects with IFM value higher than median.
\end{tabular}

Table 3. Anthropometric characteristics of participants divided into groups according to ILM median values

\begin{tabular}{|c|c|c|c|c|}
\hline \multirow[b]{2}{*}{ Variable } & \multicolumn{2}{|c|}{ Women $(n=125)$} & \multicolumn{2}{|c|}{ Men $(n=87)$} \\
\hline & $\begin{array}{c}\text { ILM }<1616 \\
(\mathrm{n}=61)\end{array}$ & $\begin{array}{c}\text { ILM }>1616 \\
(n=64)\end{array}$ & $\begin{array}{c}\text { ILM }<4290 \\
(n=44)\end{array}$ & $\begin{array}{c}\text { ILM }>4290 \\
(\mathrm{n}=43)\end{array}$ \\
\hline Fat (kg) & $17.5 \pm 8.9$ & $16.5 \pm 8.2$ & $10.2 \pm 5.6^{* *}$ & $14.6 \pm 5.8$ \\
\hline FFM (kg) & $42.2 \pm 4.1^{* * *}$ & $47.7 \pm 8.3$ & $61.5 \pm 4.3^{* * *}$ & $73.0 \pm 5.9$ \\
\hline IFM & $2.75 \pm 1.69$ & $2.18 \pm 0.82$ & $1.16 \pm 0.30$ & $1.51 \pm 0.24$ \\
\hline ILM & $1411.5 \pm 166.4^{* * *}$ & $2002.1 \pm 1000.2$ & $3663.8 \pm 488.9 * * *$ & $5117.6 \pm 799.3$ \\
\hline Z-score & $-0.981 \pm 0.782^{* *}$ & $-0.558 \pm 0.693$ & $-0.432 \pm 0.854^{*}$ & $-0.048 \pm 0.569$ \\
\hline
\end{tabular}

Irrespective of gender, participants with higher ILM but similar IFM, were characterized by markedly higher Z-score vs. their counterparts with low ILM (Tab. 3).

\section{DISCUSSION}

To the best of the authors' knowledge, the presented study is the first in which IFM and ILM have been used, and new indices of body composition o evaluate associations between body composition and bone mineral density in 
young men and women. In addition, the data obtained, together with that of Nouvenne et al. [16], suggest that the IFM-BMD relationship in women is observed irrespective of their age. Furthermore, comparison of the currentr data with other studies indicate that the body fat-BMD relationship in women, but not in men, is not related to the method of body fat evaluation $[18,19]$.

As mentioned earlier, the effect of gender on body fat - BMD associations is still under debate. However, it is postulated that leptin secretion from adipose tissue in women is greater than in men, and consequently its influence on $\mathrm{BMD}$ is more potent and reflected by significant correlations between BMD and indices of body fat [20].

A significant effect of ILM on BMD, irrespective of gender, found in the presented study is in agreement with other data indicating that the method of lean body mass assessment is of minor importance $[21,22]$. On the other hand, it should be stressed that the mechanism of associations between body composition and BMD is far from being fully elucidated $[23,24]$.

However, it is worth noting that this study has some limitations. The most important is related to the small area of skeleton in which mineral density was evaluated. This seems especially important, since recent data have indicted that in both genders body fat affects BMD in a side-specific manner [25]. Thus, validity of new indices of body composition (IFM and ILM) has to be confirmed in different skeleton compartments. In addition, most of the male participants in the current were lean in contrast to the female counterparts who were characterized by higher incidents of overweight and obesity. In consequence, the data obtained did not provide information concerning IFM and ILM associations with BMD in overweight and/or obese men.

\section{CONCLUSIONS}

The results of the study indicate the following:

1) Index of lean mass (ILM) is markedly associated with wrist bone mineral density in both genders.

2) The relationship between index of fat mass (IFM) and wrist bone mineral density is observed exclusively in young women.

\section{Acknowledgements}

The study was supported by Grant No. Ds.-181 from the Józef Piłsudski Academy of Physical Education in Warsaw, Poland.

\section{Conflict of interest}

The authors declare that they have no conflicts of interest.

\section{REFERENCES}

1. Wetzsteon RJ, Zemet BS, Shults J, Howard KM, Kibe LW, Leonard MB. Mechanical loads and cortical bone geometry in healthy children and young adults. Bone 2011; 48(5): 1103-1108.

2. Sharma S, Tandon VR, Mahajan S, Mhajan V, Mahajan A. Obesity: Friend or foe for osteoporosis. Journal of Mid-life Health 2014; 5(1): 6-9.

3. Hoy CL, Macdonald HM, McKay A. How does bone quality differ between healthy-weight and overweight adolescents and young adults? Clin Orthop Relat Res. 2013; 47(4): 1214-1225.

4. LeBrasseur LK, Achenbch SJ, Melton III LJ, Amin S, Khosla S. Skeletal muscle mass is associated with bone geometry and microstructure and serum insulin-like growth factor binding protein-2 levels in adult women and men. J Bone Miner Res. 1012; 27(10): 2159-2169.

5. Wu Ch-H, Yang K-CH, Chang H-H, Yen J-F, Tsai J-F, Huang K-Ch, et al. Sarcopenia is related to increased risk for low bone mineral density. J Clin Densitom. 2013; 16(1): 98-103.

6. Morseth B, Emaus N, Jørgensen L. Physical activity and bone: the importance of various mechanical stimuli for bone mineral density. A review. Norsk Epidemiol. 2011; 20(2): 173-178.

7. Castro JP, Joseph LA, Shin JJ, Arora SK, Nicasio JP, Shatzkes J, et al. Differential effect of obesity on bone mineral density in White, Hispanic and African American women: a cross sectional study. http://www/ nutritionandmetabolism.com/content $/ 2 / 1 / 9$

8. Greco EA, Fornari R, Rossi F, Santiemma V, Prossomariti G, Aversa A, et al. Is obesity protective for osteoporosis? Evaluation of bone mineral density in individuals with high body mass index. Int J Clin Pract. 2010; 64(6); 817-820.

9. Wu N, Wang Q-P, Li H, Wu X-P, Sun Z-Q, Luo X-H, et al. Relationships between serum adiponectin, leptin concentrations and bone mineral density, and bone biochemical markers in Chinese women. Clin Chim Acta 2010; 411(9-10): 771-775.

10. Stunes AK, Westbroek I, Gordeladze JO, Gustafsson BI, Reseland JE, Syversen U, et al. Systemic leptin administration in supraphysiological doses maintains bone mineral density and mechanical strength despite significant weight loss. Endocrinology 2012; 153(5): 2245-2253.

11. Svejme O, Ahlborg HG, Nilsson JA, Karlsson MK. Early menopause and risk of osteoporosis, fracture and mortality: a 34-year prospective observational study in 390 women. BJOG 2012; 119(7): 810-816.

12. Makovey J, Naganthan V, Sambrook P. Gender differences in relationships between body composition components, their distribution and bone mineral density: a cross-sectional opposite sex twin study. Osteoporosis Int. 2001; 16: 1495-1505.

13. Yoo H-J, Park SM, Yang SJ, Kim TN, Lim K II, Kang JH, et al. The differential relationship between fat mass and bone mineral density by gender and menopausal status. J Bone Miner Metab. 2012; 30: 47-53.

14. Zillikens MC, Uitterlinden AG, van Leeuwen JPTM, Berends AL, Henneman P, van Dijk KW, et al. The role of body mass index, insulin, adiponectin in the relation between fat distribution and bone mineral density. Calcif Tissue Int. 2010: 86: 116-125.

15. Baker JF, Davis M, Alexander R, Zemel BS, Mostoufi-Moab S, Shults J, et al. Associations between body composition and bone density and structure in men and women across the adult age spectrum. Bone 2013; 53(1): 34-41.

16. Nouvenne A, Ticinesi A, Guerra A, Folesani G, Allegri F, Pinelli S, et al. On influence of lean and fat mass on bon mineral density and on urinary stone risk factors in healthy women. http://www.translationalmedicine.com/content/11/1/248

17. WHO scientific group on the assessment of osteoporosis at primary health care level. Summary Meeting Report Brussels, Belgium, 5-7 May 2004.

18. Kim W, Chung SG, Kim K, Seo HG, Oh B-M, Yi Y, et al. The relationship between body fat and bone mineral density in Korean men and women. J Bone Miner Metab. 2013 (doi:10.1007/s00774-013-055-7).

19. Arimatsu M, Kitano T, Kitano N, Futatsuka M. Correlation between bone mineral density and body composition in Japanese females aged 18-40 years with low forearm bone mineral density. Environ Health Prev Med. 2009; 14: 46-51.

20. Sienkiewicz E, Magkos F, Aronis KN, Brinkoetter M, Chamberland JP, Chou $S$, et al. Long-term metreleptin treatment increases bone mineral density and content at the lumbar spine of lean hypoleptinemic women. Metabolism 2011; 60(9) 1211-1221.

21. Namwongprom S, Rojanasthien S, Soontrapa S, Wongboontan Ch, Ongphiphadhanakul B. Effect of fat mass and lean mass on bone mineral density in postmenopausal and perimenopausal Thai women. Int J Women's Health 2013; 5: 87-92.

22. Hu WW, Zhang H, Wang C, Gu JM, Ke YH, Fu WZ, et al. Lean mass predicts hip geometry and bone mineral density in Chinese men and women and age comparisons of body composition. J Clin Densitom. 2012; 15(4): 434-442.

23. Kaji H. Interaction between muscle and bone. J Bone Metab. 2014; 21: $29-40$.

24. Rolfe RA, Nowlan NC, Kenny EM, Cormican P, Morri DW, Prendergast PJ, et al. Identification of mechanosensitive genes during skeletal development: alteration of genes associated with cytoskeletal rearrangement and cell signaling pathway. BMC Genomics 2014: 15: 48 http://www.biomedcentral.com/1471-2164/15/48

25. Frank AW, Labas MC, Johnston JD, Kontulainen SA. Site-specific variance in radius and tibia bon strength as determined by muscle size and body mass. Physiotherapy Canada 2012; 64(3): 292-301. 